\title{
Türkiye'de Yatırım Teşvikleri ve Sabit Yatırımların İstihdam Üzerine Etkisi: Panel Veri Analizi
}

\author{
Effect on Employment of the Investment Incentives and Fixed Investments in Turkey: \\ Panel Data Analysis
}

Sibel SELIM ${ }^{1}$, O. Murat KOÇTÜRK², PInar ERYIĞiT³

\begin{abstract}
ÖZET
Teşvikler, uzun süreden beri gelişmiş ve gelişmekte olan ülkelerde ülkenin refahını arttırmak ve bölgesel dengesizlikleri ortadan kaldırmak için hükümetler ve karar alıcılar tarafından izlenen ekonomik politika araçlarındandır. Devlet, teşvikler sayesinde kendi bütçesiyle yatıım yapamadığı yerlere özel teşebbüsün imkanlarını kullanarak yatırım yapılmasını sağlayabilmektedir. Bu çalışmanın amacı, Türkiye'de 20012012 yılları arasında 81 ilde düzenlenen yatırım teşvik belgelerinin ve sabit yatıımların istihdama olan etkisini panel regresyon model kullanılarak incelemektir. Bu çalışmadan elde edilen bulgular hem teşvik sayısının hem de sabit yatırımların istihdam üzerindeki etkisinin istatistiki olarak anlamlı ve pozitif olduğunu göstermiştir.
\end{abstract}

Anahtar Kelimeler: Yatırım teşvikleri, sabit yatırımlar, istihdam, panel veri analizi

\section{GíRiş}

Ekonomi biliminde teşvikler, belirli ekonomik faaliyetlerin diğerlerine oranla daha hızlı ve fazla gelişmesini sağlamak amacıyla, devlet tarafından verilen maddi veya gayri maddi destek, yardım ve özendirmelerdir (Serdengeçti, 2000:1; Yayar ve Demir, 2012:121; Çiloğlu, 1997:1). Teşvikler, hem gelişmiş, hem de gelişmekte olan ülkeler tarafından en sık kullanılan ekonomik araçlardan biridir. UNCTAD (2000:3) tarafından küresel düzeyde yapılan bir araştırma, gelişmişlik düzeyine bakılmaksızın dünyadaki tüm ülkelerin teşviklere başvurduğunu göstermektedir. Bu araştırmanın sonuçları, yeryüzündeki hemen hemen bütün ülkelerin spesifik sektörleri hedefleyen teşvikler sunduğunu, ülkelerin \%90'ından fazlasının yerli veya yabancı yatırımcılar için ihracat teşvikleri sağladığını, $\% 85^{\prime}$ inin mali teşvikler önerdiğini, \%71'inin finansal teşvikler sağladığını ve \%70'inin de az gelişmiş yöreler için bölgesel teşvikler verdiğini ortaya koymuştur (Yavan, 2012:10). Teşvikler, son yıllarda gerileyen sek-

\begin{abstract}
Incentives are the instruments of economic policy followed by decision makers and governments to eliminate regional imbalances and for the country's well-being in developed and developing countries for a long time. State can provide investment through incentives to places will not do with own budget by using the facilities of private sector investment. The aim of this study is to examine the effect on employment of the investment incentive certificates and fixed investments using panel regression model for 81 provinces in Turkey in 2001-2012. According to analysis results, the effect on employment of the investment incentives and fixed investments is statistically significant and positive.
\end{abstract}

Keywords: Investment Incentives, fixed investments, employment, panel data analysis

törlerin rekabetçi yapılarını tekrar kazanmalarında, konjonktürel dalgalanmaların etkilerini gidermede ve gelişmekte olan ülkelerde sanayileşme stratejisinin bir parçası olarak yatırım ve ihracatın özendirilmesinde sıkça kullanılmaktadır (Yayar ve Demir, 2012:121). Aynı zamanda ekonomik büyümede, istikrar sağlamada ve istihdamı arttırmada büyük öneme sahiptir. Yavan (2012)'da belirtildiği gibi teşvikler, 1960'lardan bu yana bölgelerarası dengesizlik sorununu azaltmak ve bölgesel gelişmeyi gerçekleştirmek için devlet tarafından kullanılan en önemli, ama aynı zamanda en tartışmalı bölgesel politika aracı olmuştur (Martin, 1998:527; Armstrong ve Taylor, 2000:241; Peters ve Fisher, 2004:27; Liard-Muriente, 2007:186; Schwartz vd., 2008:167). Gerek gelişmiş, gerekse Türkiye gibi gelişmekte olan bir çok ülkede istihdama ve ihracata yönelik artışları sağlayan, teknolojik gelişmelere ayak uydurabilecek, bölgelerarası gelişmişlik farklılığını engelleyebilecek ve özellikle ülke ekonomisine katkıda bulunabilecek yatırım teşvik tedbirleri uygulanmaktadır (DPT, 1991:13; Ardıç, 1994:63).

\footnotetext{
' Doç. Dr., Celal Bayar Üniversitesi, İktisadi ve İdari Bilimler Fakültesi, Ekonometri Bölümü, sibel.selim@cbu.edu.tr 
Yatırım teşvikleri ile ilgili literatürde yapılmış olan çalışmalarda daha çok yatay-kesit verileri kullanılarak analizlerin yapıldığı ve elde edilen bulguların zamanın belli bir dönemindeki mevcut durumu yansıttığı görülmektedir. Dolayısıyla bu çalışmada literatürde daha önce kullanılmayan hem kesit hem de belli bir zaman dilimi boyunca meydana gelen gelişme ve değişmeyi ele alan panel veri analizi ile Türkiye'de teşviklerin ve sabit yatırımların istihdam üzerindeki etkisi incelenerek literatüre katkı sağlanmaya çalışılmıştır.

Bu çalışmanın izleyen bölümleri şu şekilde düzenlenmiştir. İkinci bölümde konuyla ilgili literatür araştırması yer almaktadır. Üçüncü bölümde Türkiye'de yatırım teşviklerinin gelişimi ele alınmıştır. Dördüncü bölümde metodolojiye yer verilmiştir. Uygulamanın yer aldığı beşinci bölümde çalışmanın kapsamı, kullanılan veri ve değişkenler ile analizlerden elde edilen bulgular sunulmuştur. Altıncı bölüm ise sonuç bölümünden oluşmaktadır.

\section{LITERATÜR ARAŞTIRMASI}

Günümüzün önemli konularından biri olan teşviklerin mevcut bölge ekonomisine ve kalkınmasına olan faydası ile ilgili çalışmalardan bazıları aşağıda sunulmuştur:

Dicken ve Ticknell (1992), Kuzey İngiltere'de yapılan yurt içi bölgesel teşviklerin bölgesel ve ulusal rekabete katkı sağladığını ifade etmiştir. Schalk ve Gerhard (2000)'ın 1978-1989 dönemi içinde Batı Almanya'da bölgesel yatırım teşviklerinin, bölgesel talep (yatırım ve işçilik), büyüme ve kişi başına düşen gelire olan etkilerinin incelendiği çalışmasında uzun dönemde bölgesel yatırım teşvikleri ile ilişkilerine yer verilmektedir. Çalışmanın ampirik sonuçlarına göre, diğer ülkelerde yapılan çalışmaların aksine Almanya'da bölgesel yatırım teşviklerinin istihdama olumlu etkilerinin olduğu belirtilmiştir. Blomström vd. (2003), ev sahibi ülkelerin yabancı yatırımları ülkelerine çekerek istihdam, ihracat ve vergi gelirlerinde artış olacağını belirtmektedir. Ayrıca çalışmada, yabancı sermayeli şirketleri ülkelerinde yatırım yapmaya teşvik etmek için şirketlere, vergiden muafiyet ya da vergi indirimi gibi mali teşviklerin verildiği ifade edilmektedir. Ayele (2006), 1990'larda Etiyopya'da yerli küçük ve orta ölçekli işletmeler (KOBi) için yatırım indiriminin etkilerini incelemiştir. Bu çalışmadan elde edilen bulgular en az destek alan bölgelerde uygulanan teşviklerin büyük bir bölümünü sanayi sektörünün aldığını ve yerli KOBil'ler ve Etiyopya'da bölgesel kalkınmayı desteklemede teşviklerin önemli bir politika aracı olduğunu göstermiştir. Bondonio ve Greenbaum (2006), 1989 yılından bu yana, Avrupa Birliği ülkeleri arasında bölgesel ekonomik ve sosyal uyumu teşvik etmek amacıyla Avrupa Bölgesel Kalkınma Fonu aracılığıyla yatırım teşvikleri uygulandığı- nı belirtmiştir. Çalışmanın bulguları, teşviklerin istihdam artışına neden olduğunu göstermiştir. Verdugo (2006), Meksika'da yatırım teşvikleri olarak hızlandırılmış amortisman reformları üzerine bir ampirik çalışma yapmıştır. Petrakis (2012), Yunan ekonomisinde, kaynak tahsisi konusunda teşvik politikalarını şekillendirmenin etkili olduğunu belirtmiştir.

Gelişmekte olan bir ülke olarak Türkiye'de teşviklere yönelik teorik çalışmalar bulunmakla birlikte ampirik çalışmalar oldukça sınırlı sayıdadır. Ay (2005), 1980-2003 verilerini kullanarak sabit sermaye yatırımları ve yatırım teşvikleri arasındaki ilişkiyi regresyon analizi ile araştırmış ve Türkiye'de yatırım teşviklerinin toplam sabit sermaye yatırımlarını pozitif yönde etkilediği sonucunu bulmuştur. Ayrıca elde edilen bulgulara göre, yatırım teşviklerindeki \%1'lik bir değişme toplam sabit sermaye yatırımlarını \%1.04 arttırmaktadır. Akan ve Arslan (2008)'da Doğu Anadolu Bölgesinde uygulanan teşvikler ile istihdam arasındaki ilişki, ADF birim kök testleri ile bu değişkenlerin durağanlıkları hesaplandıktan sonra regresyon analizi ile incelenmiş ve çalışmada teşvikli yatırımlar ile istihdam arasında doğrusal bir ilişkinin olduğu ve teşvikli yatırımların bölgedeki istihdamı arttırdığı sonucu bulunmuştur. Yavuz (2010) yaptığı çalışmada istihdam ve teşvikler arasındaki ilişkiyi Pearson korelasyon ve regresyon analizi ile hesaplayarak aralarında anlamlı ve yüksek derecede pozitif bir ilişki olduğunu ortaya koymuştur. Ayrıca sektörel verilerde teşvikler ile istihdam arasındaki ilişkiyi açığa çıkarmıştır. Gülmez ve Yalman (2010), Sivas'ta faaliyet gösteren KOBi'lerin halen yürürlükte olan teşviklerden ne derece yararlandıkları, Sivas'taki KOBi'lerin teşviklere bakış açılarını, teşviklerle beraber KOBi'lerin faaliyetlerindeki değişikliklerin neler olduğunu belirlemeye çalışmıştır. Toplam 38 KOBI yöneticisi araştırma kapsamına alınmıştır. Verilerin değerlendirilmesinde frekans dağıIımları, Ki Kare analizi ve t testi uygulanmıştır. Yavan (2011b), Türkiye'de illere verilen yatırım teşviklerinin bölgesel ekonomik büyüme üzerindeki etkisini regresyon analizi ile incelemiştir. Elde edilen sonuçlar, Türkiye'de uygulanan yatırım teşviklerinin bölgesel düzeyde ekonomik büyümeye katkı sağladığını ortaya koymuştur. Şahin ve Uysal (2011), Türkiye'de yatırım teşviklerinin bölgesel dağılımındaki değişimlerini bölgesel kalkınma çerçevesinde analiz etmiştir. Çalışmada 2002-2009 dönemi için Shift-Share tekniği kullanılmıştır. Bölgelerin teşvik almada uzmanlaştıkları sektörler ve teşvik piyasasında paylarını artırma durumları incelenmiştir. Yavan (2012), teşviklerin bölgesel düzeyde tahsisi ve dağılımını belirleyen faktörlerin neler olduğunu ve Türkiye'de 2001-2008 döneminde illere verilen yatırım teşviklerinin hangi faktörler tarafından belirlendiğini regresyon analizi ile test etmiştir. 
Elde edilen deneysel bulgular Türkiye'de illere verilen teşviklerin mekânsal tahsisinin sadece ekonomik faktörler tarafından değil, aynı zamanda politik, küresel ve kurumsal faktörler tarafından belirlendiğini ortaya koymaktadır. Ayrıca bu çalışmada gelir düzeyi, sanayi yatırımlarının seviyesi, dış ticarete açıklık derecesi, politik güç, iktidar partisinin ideolojisi ve kalkınmada öncelikli yöre statüsüne sahiplik değişkenlerinin bir il/ bölgeye giden teşviklerin miktarını belirleyen etkenler olduğunu ortaya koyulmuştur.

\section{TÜRKIYE'DE YATIRIM TEŞVIKLERININ GELIşimi}

Teşvikler, Türkiye ekonomisinin gelişmesinde her zaman çok önemli bir yer teşkil etmiştir. Türkiye, özel sektörün daha çok yatırım yapmasını sağlamak, bu yatırımları belirli sektörlere ve bölgelere yönlendirmek ve ülke içindeki bölgesel gelişmişlik farklılıklarını azaltmak amacıyla, 1913 yılında çıkarılan Teşvik-i Sanayi Kanunu'ndan bu yana, özellikle de 1968 yılından bugüne ekonomik ve bölgesel gelişmesini sağlamak için düzenli olarak teşvikler vermiştir (Yavan, 2011a).

Türkiye'de yıllar itibariyle teşvik sistemleri incelendiğinde bölgesel önceliklere dayalı uygulamaların ağırlık kazandığı izlenmektedir. 1913 yılından beri uygulanan teşviklerin uzun yıllar bölgesel önceliklere dayalı sistemler içermiş olmasına rağmen, bugünkü istatistiklere bakıldığında bölgelerarası farklııkları gidermede başarılı olmadığı görülmektedir (Çiloğlu, 2000: 31). Uygulanan teşvik tedbirleri, bazı dönemler, hedeflenen amaçlara gereği gibi ulaşamadığı iddiasıyla birçok ortamda eleştiri konusu olmuştur (Gülmez ve Yalman, 2010:240).

1990 yılı sonrasında ortaya çıkan küreselleşmenin etkisiyle teşvikler ülkemizde daha da önem kazanmaya başlamıştır. Teşvik türleri ve faaliyet alanları uygulamaya başladığından günümüze kadar çeşitli değişikliklere uğramıştır. Önceleri düşük faizli krediler, arsa tahsisleri, devletin sermaye katılımı, enerji indirimleri, nakit hibe destekleri, vergi muafiyetleri ve istisnaları, devlet garantileri, kamu alımları gibi teşvik araçları kullanılırken günümüzde bunlara ek olarak ihracat, yatırım, istihdam, doğrudan yabancı sermaye yatıımlarının çekilmesi, AR-GE faaliyetleri, KOBi'lerin gelişimi, çevrenin korunması gibi alanlara da yayılmıştır (Narin, 2012:5). $2000^{\prime}$ li yıllarda uygulanan yatıım teşvikleri ekonomik krizlerden etkilenmiştir. 1999 ve 2001 krizlerinde özellikle teşvikler için kaynak yetersizliği sıkıntısı ortaya çıkmış ve uygulanacak olan yeni teşvik programlarında gecikmeler gerçekleşmiştir. Ayrıca bürokrasinin fazlalığı ve uygulama mevzuatındaki sürekli değişiklikler yatırım teşviklerinden istenilen oranda verim alınamamasına neden olmuştur (Karaca, 2004:53). Türkiye'nin günümüz teşvik sisteminin en önemli sorunları, karmaşıklık, etkin destek araçlarının bulunmayışı, eşgüdüm eksikli- ği ve performans izleme mekanizmalarının yetersizliği olarak belirtilmiştir (Devlet Planlama Teşkilatı, 2006:30). Ayrıca Dokuzuncu Kalkınma Planı (2009-2013)'nda yatırım teşvik politikaları şu şekilde belirlenmiştir: Odaklanmanın artırılarak kaynak etkinliğinin sağlanması, ekonominin yapısal dönüşümüne katkı sağlayabilecek yenilikçi, rekabet edebilir, dinamik ve yüksek katma değer yaratabilen öncü sektörlerin seçilmesi ve bölgesel boyutta, bölgelerin gelişme potansiyelleri doğrultusunda sektörel yatırım konularının belirlenerek destek sisteminin oluşturulması. (Devlet Planlama Teşkilatı, 2006:99). 2014-2018 yıllarını kapsayan Onuncu Kalkınma Planı (2013)'nda belirtildiği üzere bölgesel gelişme ve bölgesel rekabet edebilirlik alanında; merkezde ve mahallinde kurumsal yapılar oluşturulmuş, eyleme dönük muhtelif programlar uygulanmıştır. Bu kapsamda, merkezi düzeyde Bölgesel Gelişme Yüksek Kurulu ve Bölgesel Gelişme Komitesi kurulmuş, bölgesel düzeyde 26 kalkınma ajansı ve bunların bünyesinde 81 ilde yatırım destek ofisleri faaliyete geçirilmiş, tüm ülke için bölgesel gelişme planları hazırlanmış ve uygulamaya konulmuştur (Kalkınma Bakanlığı, 2013:27).

Türkiye'de yatırımları arttırmaya yönelik olarak başta Hazine Müsteşarlığı ve Devlet Planlama Teşkilatı olmak üzere çeşitli kuruluşlarca teşvik belgeleri esasına göre ve ilgili kanun, yönetmelik ve tüzükler yoluyla kalkınma planlarında belirlenen çerçeve dâhilinde yatırımlara yönelik teşvikler uygulanmaktadır (Yalçın, 1999:18). Türkiye'de 2001-2012 yılları arasında 81 il için toplam yatırım teşvik belge adedi, teşviklerle sağlanan toplam istihdam ve teşviklerle yapılmış olan toplam sabit yatırımları Tablo 1'de verilmiştir.

Tablo 1'de 2001-2012 dönemindeki yatırım teşviklerinin gelişimi genel olarak değerlendirildiğinde, bazı yıllarda, örneğin 2006, 2007 ve 2009 yıllarında, teşviklerde büyük düşüşler meydana gelmiştir. Teşvik belgesi talebindeki artışın söz konusu dönemlerde düşüş trendine girmesinin esas sebebi, 2006 yılı itibariyle yatırım teşvik sisteminde önemli bir yer teşkil eden yatırım indiriminin teşvik sisteminden çıkartılmasıdır (DPT, 2007:17-18). Ayrıca 2008 yılında küresel finansal krizin patlak vermesi Türkiye ekonomisini ciddi biçimde sarsmış olmasına rağmen, söz konusu yılda firmaların yatırım eğiliminde küçük ölçekli de olsa artış sözkonusu olmuştur. 2009 yılında ise, derinleşen dünya finansal krizinin Türkiye ekonomisini derinden etkileyerek firmaların yatırım eğilimini azalttığı görülmektedir. Buna karşılık 2010 yılında yatııım teşvik belgesi sayısının azalmaması hatta krizin etkilerinin devam etmesine rağmen bir miktar artması, yeni teşvik sisteminin 2009 yılı ortalarında devreye girmesi ve yatırımcılar tarafından olumlu yönde ilgi görmesi ile açıklanabilir (Yavan, 2012:15). 
Tablo 1: Türkiye'de 2001-2012 Dönemi Toplam Yatırım Teşvik Belgeleri, İstihdam ve Sabit Yatırımlar

\begin{tabular}{|c|c|c|c|}
\hline Yıllar & $\begin{array}{c}\text { Toplam Yatırım Teşvik } \\
\text { Belge Adedi }\end{array}$ & Toplam İstihdam & $\begin{array}{c}\text { Toplam Sabit Yatırım } \\
\text { (Milyon TL) }\end{array}$ \\
\hline 2001 & 2051 & 105731 & 12367 \\
\hline 2002 & 2701 & 139641 & 12883 \\
\hline 2003 & 3336 & 149040 & 14640 \\
\hline 2004 & 3614 & 166943 & 16946 \\
\hline 2005 & 4074 & 180226 & 18893 \\
\hline 2006 & 2905 & 118639 & 16383 \\
\hline 2007 & 2823 & 128547 & 22181 \\
\hline 2008 & 3051 & 118158 & 27164 \\
\hline 2009 & 2381 & 87289 & 30884 \\
\hline 2010 & 4324 & 155426 & 64862 \\
\hline 2011 & 4492 & 128390 & 56179 \\
\hline 2012 & 4362 & 149234 & 57763 \\
\hline Toplam & 40.114 & 1.627 .264 & 351.145 \\
\hline
\end{tabular}

(Kaynak: Ekonomi Bakanlığı, Teşvik Uygulama ve Yabancı Sermaye Genel Müdürlüğü)

Ancak genel olarak 2001 -2012 yılları dikkate alındı- gelerinde öngörülen yatırım tutarı 351.145 milyon TL'yi ğında teşvik belgesi sayısının, teşvikli yatıım tutarının bulmuş ve verilen bu teşvikler sonucu 1.627.264 istihve istihdamın söz konusu dönemde artış eğilimi gös- dam yaratılmıştır. Tablo 2'de ise yatırım teşvik belgeleterdiği görülmektedir. 12 yıllık dönemde 40114 adet rinin, sabit yatırımlar ve istihdamın 2001-2012 yılları yatııım teşvik belgesi verilmiş olup, verilen teşvik bel- arasındaki sektörel bazdaki değişimi görülmektedir.

Tablo 2: Türkiye'de Toplam Yatıım Teşvik Belgeleri, İstihdam ve Sabit Yatııımların Sektörel Dağılımı

\begin{tabular}{|c|c|c|c|c|c|c|c|c|c|c|c|c|}
\hline \multicolumn{13}{|c|}{ Toplam Yatırım Teşvik Belge Adedi } \\
\hline Sektör & 2001 & 2002 & 2003 & 2004 & 2005 & 2006 & 2007 & 2008 & 2009 & 2010 & 2011 & 2012 \\
\hline Enerji & 46 & 33 & 43 & 42 & 84 & 54 & 92 & 137 & 112 & 162 & 212 & 197 \\
\hline Hizmet & 653 & 835 & 1102 & 1215 & 1706 & 1212 & 800 & 659 & 545 & 1076 & 1251 & 1157 \\
\hline İmalat & 1234 & 1711 & 2009 & 2169 & 2062 & 1435 & 1707 & 2024 & 1493 & 2335 & 2484 & 2594 \\
\hline Madencilik & 64 & 86 & 118 & 144 & 134 & 124 & 124 & 135 & 140 & 259 & 289 & 288 \\
\hline Tarım & 54 & 36 & 64 & 44 & 88 & 80 & 100 & 96 & 91 & 492 & 256 & 126 \\
\hline Toplam & 2051 & 2701 & 3336 & 3614 & 4074 & 2905 & 2823 & 3051 & 2381 & 4324 & 4492 & 4362 \\
\hline & \multicolumn{12}{|c|}{ Toplam İstihdam (Teşviklerin Sağladığı) } \\
\hline Enerji & 1034 & 388 & 1902 & 1542 & 731 & 543 & 4041 & 4466 & 1990 & 3003 & 4620 & 3503 \\
\hline Hizmet & 31698 & 39106 & 47616 & 53983 & 73197 & 49617 & 40989 & 40711 & 28463 & 54472 & 42143 & 57630 \\
\hline İmalat & 68081 & 90858 & 82632 & 100009 & 94900 & 60732 & 76742 & 66045 & 50789 & 77228 & 68566 & 76876 \\
\hline Madencilik & 2215 & 5614 & 14116 & 7041 & 7686 & 4295 & 4159 & 4598 & 3694 & 5745 & 5929 & 8124 \\
\hline Tarım & 2703 & 3675 & 2774 & 4368 & 3712 & 3452 & 2616 & 2338 & 2353 & 14978 & 7132 & 3101 \\
\hline \multirow[t]{2}{*}{ Toplam } & 105731 & 139641 & 149040 & 166943 & 180226 & 118639 & 128547 & 118158 & 87289 & 155426 & 128390 & 149234 \\
\hline & \multicolumn{12}{|c|}{ Toplam Sabit Yatırım (Milyon TL) } \\
\hline Enerji & 1484 & 593 & 459 & 678 & 1387 & 737 & 3952 & 10846 & 9693 & 9326 & 15577 & 12562 \\
\hline Hizmet & 4065 & 4354 & 6991 & 8028 & 8171 & 9334 & 9555 & 8455 & 8255 & 16383 & 14938 & 15218 \\
\hline İmalat & 6668 & 7295 & 5765 & 7830 & 8309 & 5563 & 7961 & 7036 & 11531 & 34079 & 22590 & 26973 \\
\hline Madencilik & 79 & 551 & 1292 & 301 & 805 & 486 & 504 & 583 & 1021 & 1997 & 1460 & 2213 \\
\hline Tarım & 71 & 90 & 133 & 109 & 221 & 263 & 209 & 244 & 384 & 3077 & 1614 & 797 \\
\hline Toplam & 12367 & 12883 & 14640 & 16946 & 18893 & 16383 & 22181 & 27164 & 30884 & 64862 & 56179 & 57763 \\
\hline
\end{tabular}

( Kaynak: Ekonomi Bakanlığı, Teşvik Uygulama ve Yabancı Sermaye Genel Müdürlüğü) 
Tablo 2'den de görüldüğü gibi 2010 yılında ilk sırayı imalat sektörü almakta bu sektörü hizmetler, enerji, tarım ve madencilik sektörleri izlemektedir. Fakat istihdam açısından enerji sektörü tarım ve madencilik sektörlerinin gerisinde kalmaktadır. 2011 yılında yatırım tutarı açısından ilk sırayı yine imalat sektörü alırken bu sektörü enerji, hizmet, tarım ve madencilik izlemektedir. Ancak istihdam açısından imalat sektörü birinci sırayı alırken enerji sektörü son sırada yer almaktadır. 2012 yılında ise son sırayı tarım sektörünün aldığı ve istihdam açısından da son sırada tarım sektörünün olduğu görülmektedir.

\section{METODOLOJI}

Baltagi (2008) panel veriyi, ülkeler, firmalar, hanehalkları, vb. kesit gözlemlerinin belli bir zaman dönemi içinde bir araya getirilmesi olarak tanımlamaktadır. Diğer bir deyişle, zaman boyutuna sahip kesit verilerini kullanarak ekonomik ilişkilerin tahmin edilmesine panel veri analizi adı verilmektedir. Bu analizde zaman serileri ile kesit serileri birleştirilerek, hem zaman hem de kesit boyutuna sahip veri seti oluşturulmaktadır (bkz. Hsiao, 1985).

Panel veri kullanmanın faydaları şu şekilde sıralanmaktadır (Baltagi, 2008: 6-8, Hsiao, 2003: 3-7, Kennedy, 2006: 331, 2001, Gujarati, 2004: 637-638): Panel veride, bireylerin, firmaların, illerin ya da ülkelerin farklılıklara sahip olduğu düşünülmektedir. Panel veride gözlem sayısı daha fazla olduğundan daha iyi tahminlerin yapılmasını sağlamaktadır. Panel veri daha ayrıntılı veri, daha fazla değişkenlik, değişkenler arasında daha az çoklu doğrusal bağlantı, daha çok serbestlik derecesi ve etkinlik verir. Panel veri sadece kesit ya da zaman serisi analizleriyle ortaya konamayacak etkilerin elde edilmesini sağlamaktadır. Sabit, eğim katsayısı ve hata terimi hakkında yapılan varsayımlara bağlı olarak panel veri regresyonu farklı şekillerde tahmin edilmektedir. Panel veri regresyon modelini aşağıdaki gibi ifade etmek mümkündür (Baltagi, 2008: 13; Erkan, 1999: 81);

$$
y_{i t}=\alpha_{i}+X_{i}^{\prime} \beta_{k}+u_{i} \quad i=1, \ldots . . N, t=1 \ldots \ldots . T
$$

şeklinde yazılabilir. Burada $a$, skaler, $\beta, \mathrm{Kx} 1$ boyutunda parametre ve $X_{i t^{\prime}} \mathrm{K}$ açıklayıcı değişken üzerinde i. gözlemin değeridir. Bu tür bir modelde, hata teriminin sıfır ortalama ve varyansla normal dağıldığı kabul edilir. Ayrıca her bir yatay kesit birim için gözlemler korelasyonsuz, birim ve zamana karşı hatalar eşit varyanslıdır (Johnston ve Dinardo, 1997: 390; Özer ve Biçerli, 2003: 71). Panel veri dengeli ve dengesiz panel olarak ikiye ayrılmaktadır. Eğer her bir zaman döneminde her bir birim için bir gözlem varsa, bu tür panel veri dengeli panel olarak adlandırılır. Bazı gözlemler eksik ise bu panel, dengesiz panel olarak adlandırılmaktadır (Dougherty, 2007: 409, Greene, 2003: 293). Bu çalışmada dengeli panel veri seti kullanılmıştır.

Panel veri modellerini sabit etkiler modeli ve tesadüfi etkiler modeli şeklinde incelemek söz konusudur (bkz. Greene, 2003). Literatürde, en çok tercih edilen model sabit etkiler modelidir. Greene (2003)'de de belirtildiği gibi sabit etkiler modelinde eğim katsayılarının zaman ve kesit birimleri için aynı olması ancak sabit katsayının yatay kesit birimlerine göre değişmesi söz konusudur. Bu modelde yatay kesit birimleri arasındaki farklar sabit terimdeki farklılıklarla açıklanmakta ve panel veri modeli kukla değişken yardımıyla tahmin edilmektedir. Bu modelde çok sayıda kukla değişkenin kullanılması nedeniyle serbestlik derecesi düşmekte ve çoklu doğrusal bağıntı problemi söz konusu olmaktadır (Kennedy, 2006: 332). Eşitlik (2)'de sabit etkiler modelinde $\beta_{2 i t}=\beta_{2^{\prime}} \beta_{3 i t}=\beta_{3}$ olduğu varsayılmaktadır. Böylece eşitlik;

$Y_{i t}=\beta_{1 i}+\beta_{2} X_{2 i t}+\beta_{3} X_{3 i t}+\ldots+\beta_{k i t} X_{K i t}+u_{i t}$

şeklinde yazılabilmektedir. , ifadesindeki $i$ harfi kesiti simgelemekte ve sabitin kesitlere göre değiştiğini göstermektedir (Gujarati, 2004; Çetin ve Ecevit, 2010:173). Tesadüfi etkiler modelinde ise, yatay kesit birimlerinde veya birimlere ve zamana göre meydana gelen değişiklikler, modele hata teriminin bir bileşeni olarak dahil edilmektedir (Baltagi, 1995:13). Tesadüfi etkiler modelinde $i$, kesitleri ve $t$ zamanı göstermek üzere aşağıdaki model tahmin edilmektedir.

$Y_{i t}=\alpha+X_{i t}{ }_{i t} \beta+\left(\mu_{i}+v_{i t}\right) \quad i=1, \ldots, N \quad t=1, \ldots, T$

Modelde $X_{i t^{\prime}}$ açıklayıcı değişkenler vektörünü; $Y_{i t^{\prime}}$ bağımlı değişkeni; $\beta$, değişken katsayılarını ve $\alpha$, sabit terimi göstermektedir. Burada hata terimlerinin, varyanslarının sıfıra eşit olacak şekilde bağımsız ve özdeş dağıldığı kabul edilmektedir. $\mu_{i^{\prime}}$ birimlerde meydana gelen gözlenemeyen tesadüfi farkları içeren hata terimi iken, $v_{i t}$ geri kalan hataları içeren terimdir (Bayraktutan ve Demirtaş, 2011:6).

Panel veri analizlerinde sabit etki ya da tesadüfi etki modellerinden hangisinin kullanılması gerektiğine karar verebilmek için Hausman Testi uygulanmaktadır. Bu test, gruba ait spesifik etkinin tesadüfi olduğunu varsayarak modelin açıklayıcı değişkenleri ile modele ait spesifik etkiler arasında korelasyon olup olmadığını belirlemeyi amaçlar (Grene, 2003: 72-73; Karaaslan ve Yıldız, 2011:10). Hausman test istatistiği ki-kare dağılımlıdır. Test istatistiği tablo değerinden daha büyük olduğu durumlarda gruba ait spesifik etkiler ile açıklayıcı değişkenler arasında ilişkinin olmadığı hipotezi reddedilir. Bu durumda, sabit etki modeli, tesadüfi etki modeline tercih edilmektedir. (Karaaslan \& Yıldız, 2011:10). 
Panel veri analiz modelinde hata terimine ait varsayımların gerçekleşmediği durumda bu varsayımlara karşı dirençli tahminciler veren esnek genelleştirilmiş en küçük kareler modeli kullanılmaktadır. Genelleştirilmiş en küçük kareler yöntemi, varyans kovaryans matrisinin bilindiği durumlarda kullanılabilmektedir. Ancak çoğu durumda varyans kovaryans matrisi bilinmemektedir ve tahmin edilmesi gerekmektedir. Bu durumda Esnek Genelleştirilmiş En Küçük Kareler Yöntemi söz konusu olmaktadır. Esnek Genelleştirilmiş En Küçük Kareler Yönteminin önemli özellikleri aşağıda sunulmuştur:

1) N'in T kadar büyük olmadığı durumda u'nun kısıtsız kovaryans matrisinin tahmininin küçük örnek performansı zayıftır.

2) Kısıtlı varyans kovaryans matrisini kullanan esnek genelleştirilmiş en küçük kareler tahmincisi varyans kovaryans matrisine kısıt koymayan genelleştirilmiş en küçük kareler tahmincisinden daha az asimptotik etkin değildir

3) Bhargava, Franzini ve Narendranathan (1982), esnek genelleştirilmiş en küçük karelerin uygulanabilmesi için, $\rho$ tahmincisini önermiştir (Tatoğlu, 2012:102).

\section{UYGULAMA}

\section{1. Çalışmada Kullanılan Veri ve Değişkenler}

Bu çalışmada Türkiye'de 2001-2012 yılları arasında 81 ilde düzenlenen yatırım teşvik belgelerinin ve sabit yatırımlarının istihdama olan etkisi panel regresyon model kullanılarak incelenmiştir. Bu amaçla çalışmanın analizlerinde kullanılan veriler, Teşvik Uygulama ve Yabancı Sermaye Genel Müdürlüğü'nden elde edilmiştir. Analizlerde kullanılan değişkenler, 2012 yılında yapılan teşviklerdeki düzenlemelerden önce mevcut yatırım teşvik belgelerinin ve sabit yatırımların istihdamı ne kadar etkilediğinin belirlenmesi amacıyla seçilmiştir. Yavan(2011a, 2011b, 2012), Yavuz (2010), Akan ve Arslan (2008) ve Ay (2005), aynı veri tabanını kullanarak yaptıkları çalışmalarda zaman serisi ya da kesit verisi kullanmışlardır. Bu çalışmada kullanılan veriler ise hem zaman hem de kesit verilerini içeren panel verilerdir. Literatürdeki çalışmalardan farklı olarak bu çalışmada 2001-2012 yılları arasında 81 il verisini içeren panel veri seti kullanıımıştır. Araştırmanın yapıldığı dönemde 01.01.2001 - 31.01.2013 tarihleri arasında düzenlenen yatırım teşvik belgeleri verileri yayınlandığı için araştırma 2001-2012 yılları ile sınırlandırılmıştır.

Bu çalışmada kullanılan değişkenlerden ilki teşvik belgesi sayısıdır. Her ne kadar, bir ile verilen teşvik belgesi sayısı, yatırım teşviklerinin büyüklüğünü yansıtan çok iyi bir gösterge olmasa da, istatistiksel analiz için kullanılabilmektedir. Bu göstergenin en önemli avantajı, parasal bir değer ifade etmediği için kolaylıkla kullanılabilmesi ve bunun yanında yatırım miktarı az veya çok olsun o bölgedeki teşvike olan talebi ortaya koymasıdır. İkinci değişken teşvikli sabit yatııım tutarıdır. Bu değişken teşvikli yatııımın miktarını en iyi yansıtan gösterge olmakla birlikte, bazı dezavantajlara da sahiptir. Değişkenin en önemli dezavantajı, Türkiye'deki teşvikli sabit yatırım tutarı verisinin gerçekleşen değil, öngörülen/taahhüt edilen olmasıdır. Üçüncü değişken ise, bu çalışmada ele alınan modele ait bağımlı değişken olup teşvikle yaratılan istihdam miktarıdır. İstihdam verisi ekonomik çalışmalarda kullanılan en iyi ölçme araçlarından biridir. Bu üç gösterge bir bölgedeki teşviklerin durumunu en iyi yansıtan yegane veri setidir (Yavan, 2012:25). Çalışmada kullanılan istihdam, teşvik belgesi sayısı ve sabit yatırımlara ait grafikler Şekil 1-3'de sunulmuştur. Analizlerde kullanılan LNIST, LNTES ve LNSY değişkenlerine ait kısaltma ifadeleri sırasıyla istihdam, teşvik sayısı ve sabit yatırımların logaritmalı hallerini göstermektedir. Şekil 1-3'de LNIST, LNTES ve LNSY verilerinin düzey değerlerinde durağan bir yapı gösterdiği görülmektedir.

LNIST

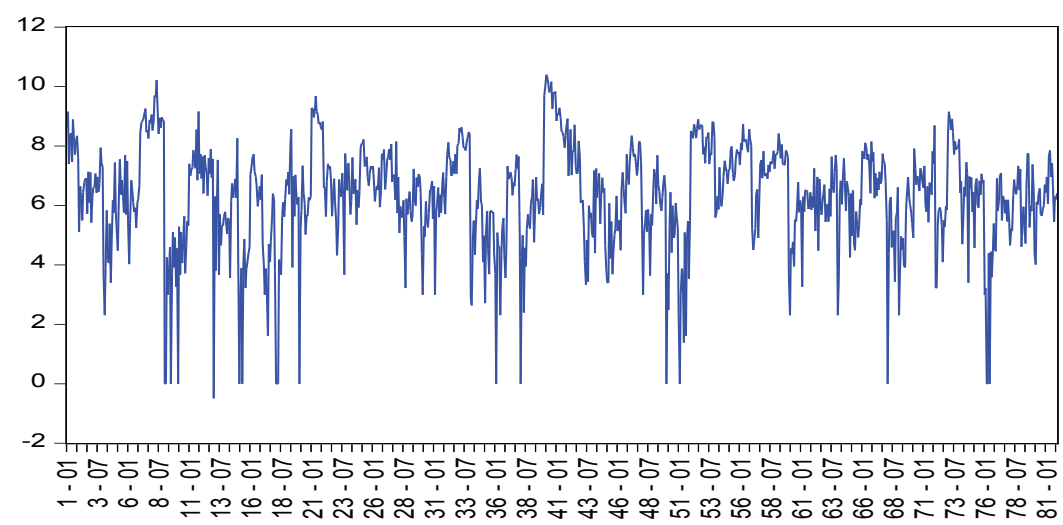

Şekil 1: İstihdam Serisinin Grafiği 
LNTES

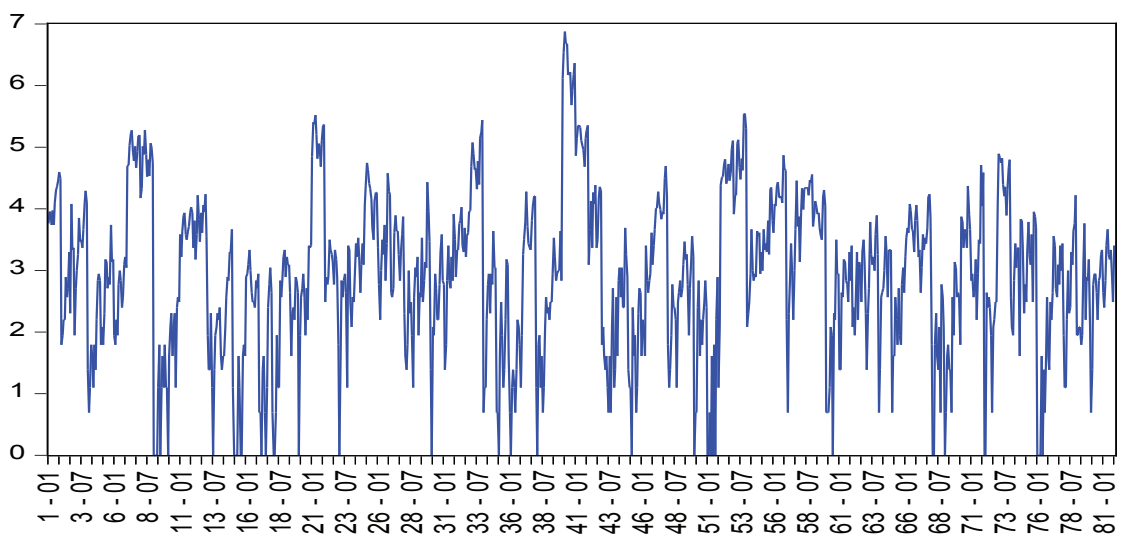

Şekil 2:Teşvik Sayıları Serisinin Grafiği

LNSY

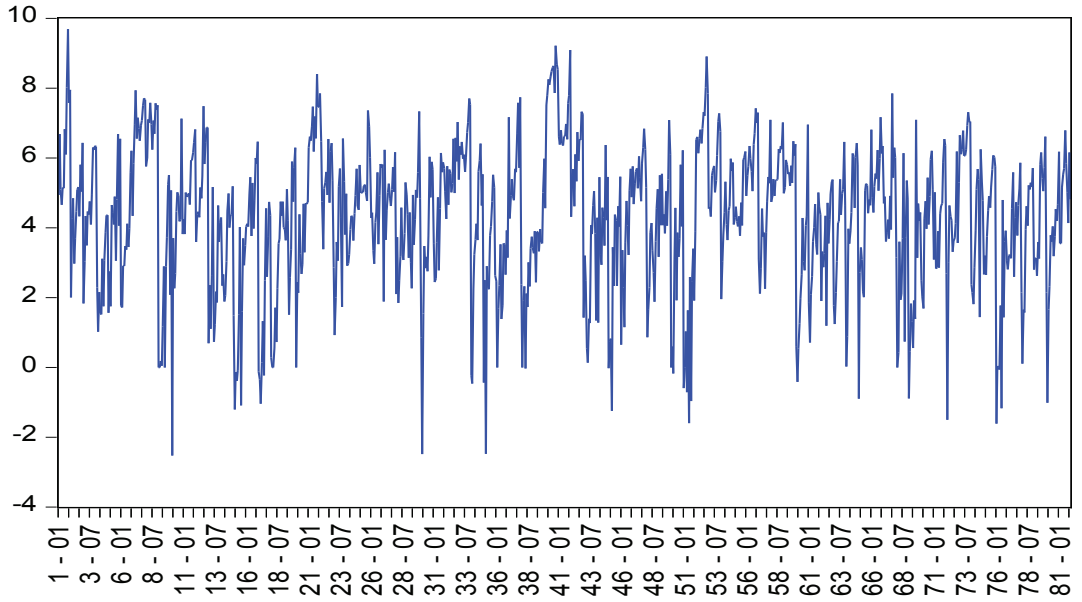

Şekil 3: Sabit Yatırım Serisinin Grafiği

Ayrıca bu çalışmada kullanılan değişkenlere ait tanımlayıcı istatistikler analiz dönemi olan 2001-2012 yılları için il bazında Tablo 3'de verilmiştir. Tablo 3'te en fazla teşvik verilen, teşvikli sabit yatıımlara sahip olan ve bu teşviklerle en çok istihdam yaratan ilin İstanbul olduğu görülmektedir. 2001-2012 yılları arasında en yüksek teşvik alan ikinci ilin Bursa olduğu görülmektedir. Bu ili İzmir, Ankara ve Konya izlemektedir. Sabit yatırımlar dikkate alındığında en fazla sabit yatı- rımlara İstanbul ilinden sonra Kocaeli, İzmir, Bursa ve Ankara sahiptir. Verilen teşviklerle en fazla istihdam sağlayan iller İstanbul'dan sonra Antalya, Bursa, Ankara ve İzmir'dir. En düşük sabit yatırımlara sahip olan ve bu sabit yatırımlarla en düşük istihdam yaratan il Adana'dır. En düşük teşvik belge sayısı ise Ardahan'a aittir. Bunu Bayburt, Tunceli ve Hakkari izlemektedir. 
Tablo 3: Tanımlayıcı İstatistikler

\begin{tabular}{|c|c|c|c|c|c|c|}
\hline \multirow[b]{2}{*}{ İller } & \multicolumn{2}{|c|}{ Teşvik Belge Sayısı } & \multicolumn{2}{|c|}{ Sabit Yatırım } & \multicolumn{2}{|c|}{ İstihdam } \\
\hline & Ortalama & $\begin{array}{r}\text { Std. } \\
\text { Sapma }\end{array}$ & Ortalama & $\begin{array}{r}\text { Std. } \\
\text { Sapma }\end{array}$ & Ortalama & Std. Sapma \\
\hline Adana & 64.25 & 20 & 2.236 & 4.492 & 4.159 & 2.358 \\
\hline Adıyaman & 19 & 15 & 155.891 & 170.785 & 699.5 & 375.993 \\
\hline Afyonkarahisar & 36.666 & 19.795 & 186.681 & 217.210 & 1046.167 & 689.533 \\
\hline Ağrı & 7.916 & 6.171 & 69.86925 & 155.272 & 286.083 & 471.032 \\
\hline Aksaray & 17.916 & 10.282 & 175.238 & 271.484 & 816 & 733.633 \\
\hline Amasya & 14.5 & 6.585 & 90.702 & 144.995 & 435.6667 & 264.575 \\
\hline Ankara & 146.750 & 31.818 & 1345.949 & 739.773 & 6705 & 1963.29 \\
\hline Antalya & 123.166 & 37.624 & 1157.213 & 580.233 & 9933.917 & 6638.87 \\
\hline Ardahan & 2.583 & 2.234 & 43.720 & 82.732 & 53.833 & 54.036 \\
\hline Artvin & 7.416 & 3.941 & 168.354 & 342.612 & 128.333 & 88.099 \\
\hline Aydın & 42.083 & 9.356 & 295.242 & 265.315 & 2526.917 & 2460.277 \\
\hline Balıkesir & 45.583 & 14.668 & 455.648 & 532.669 & 1490.167 & 676.591 \\
\hline Bartın & 8.5 & 8.836 & 35.642 & 53.669 & 361.416 & 498.588 \\
\hline Batman & 14.916 & 11.147 & 63.144 & 56.103 & 738.25 & 1026.087 \\
\hline Bayburt & 2.75 & 2.005 & 13.716 & 18.968 & 53 & 38.765 \\
\hline Bilecik & 17.25 & 4.882 & 195.499 & 184.194 & 1113.667 & 591.413 \\
\hline Bingöl & 6.833 & 6.860 & 30.204 & 41.940 & 157.416 & 192.634 \\
\hline Bitlis & 9.833 & 10.025 & 33.402 & 44.498 & 221.5 & 291.117 \\
\hline Bolu & 15.416 & 6.006 & 145.272 & 168.998 & 1233.417 & 1463.43 \\
\hline Burdur & 15.583 & 9.792 & 52.265 & 47.002 & 450.083 & 386.843 \\
\hline Bursa & 177.083 & 45.342 & 1474.541 & 1136.63 & 8585.917 & 2989.35 \\
\hline Çanakkale & 21.666 & 6.271 & 307.365 & 235.376 & 871.5 & 457.212 \\
\hline Çankırı & 13.75 & 9.215 & 132.287 & 202.444 & 703 & 629.938 \\
\hline Çorum & 21.25 & 8.389 & 88.717 & 77.447 & 792.833 & 543.832 \\
\hline Denizli & 71.25 & 23.140 & 371.524 & 449.613 & 2006.333 & 982.593 \\
\hline Diyarbakır & 38.416 & 26.969 & 147.203 & 125.624 & 1197.167 & 748.087 \\
\hline Düzce & 29.833 & 13.009 & 192.967 & 159.253 & 1702.583 & 989.690 \\
\hline Edirne & 10.75 & 6.224 & 58.303 & 60.142 & 362.083 & 258.421 \\
\hline Elazığ & 27.833 & 21.501 & 215.209 & 417.861 & 698.0833 & 376.688 \\
\hline Erzincan & 14 & 9.981 & 111.525 & 153.859 & 349.083 & 277.686 \\
\hline Erzurum & 20.666 & 12.477 & 156.544 & 154.565 & 521.583 & 319.380 \\
\hline Eskişehir & 37.166 & 10.2410 & 370.067 & 318.201 & 1859.917 & 780.364 \\
\hline Gaziantep & 127.333 & 51.807 & 782.480 & 638.657 & 3974.667 & 1033.91 \\
\hline Giresun & 14.75 & 10.234 & 148.274 & 190.273 & 392.416 & 408.412 \\
\hline Gümüşhane & 8 & 7.687 & 58.329 & 79.444 & 186.166 & 131.454 \\
\hline Hakkari & 4.25 & 2.701 & 18.981 & 15.886 & 97.083 & 77.689 \\
\hline Hatay & 45 & 16.798 & 658.859 & 771.479 & 1254.917 & 503.521 \\
\hline Iğdır & 5.916 & 3.987 & 14.675 & 13.231 & 152 & 121.860 \\
\hline Isparta & 20.166 & 8.600 & 81.137 & 105.011 & 527.333 & 287.269 \\
\hline İstanbul & 574.5 & 197.173 & 4574.198 & 2180.57 & 21145.17 & 6283.39 \\
\hline İzmir & 172.333 & 4.900 & 1651.956 & 2334.91 & 6402.5 & 2364.9 \\
\hline Kahramanmaraş & 53.333 & 21.419 & 573.052 & 481.409 & 2494.75 & 1649.49 \\
\hline
\end{tabular}




\begin{tabular}{|c|c|c|c|c|c|c|}
\hline \multirow[b]{2}{*}{ iller } & \multicolumn{2}{|c|}{ Teşvik Belge Sayısı } & \multicolumn{2}{|c|}{ Sabit Yatırım } & \multicolumn{2}{|c|}{ İstihdam } \\
\hline & Ortalama & $\begin{array}{r}\text { Std. } \\
\text { Sapma }\end{array}$ & Ortalama & $\begin{array}{r}\text { Std. } \\
\text { Sapma }\end{array}$ & Ortalama & Std. Sapma \\
\hline Karabük & 5.5 & 3.605 & 38.350 & 48.305 & 246.416 & 172.369 \\
\hline Karaman & 16.666 & 9.810 & 120.020 & 164.999 & 716.666 & 447.75 \\
\hline Kars & 6.5 & 4.833 & 49.668 & 68.055 & 163.583 & 170.118 \\
\hline Kastamonu & 17.75 & 10.454 & 98.277 & 110.074 & 693 & 625.372 \\
\hline Kayseri & 62.25 & 19.652 & 344.424 & 233.340 & 2405 & 953.532 \\
\hline Kırıkkale & 9.416 & 4.888 & 54.079 & 60.492 & 247.5 & 174.317 \\
\hline Kırklareli & 21.083 & 8.140 & 236.689 & 325.413 & 865.333 & 520.840 \\
\hline Kırşehir & 8.416 & 5.599 & 93.961 & 157.397 & 213.583 & 191.851 \\
\hline Kilis & 4.583 & 5.177 & 9.973 & 14.872 & 77 & 90.8195 \\
\hline Kocaeli & 106.083 & 26.182 & 1737.6 & 1949.86 & 5327.333 & 985.623 \\
\hline Konya & 136.666 & 70.542 & 446.481 & 453.955 & 3588.25 & 1776.96 \\
\hline Kütahya & 22.666 & 11.428 & 139.436 & 133.736 & 834.583 & 543.145 \\
\hline Malatya & 38.25 & 19.559 & 159.4897 & 161.818 & 1802.917 & 768.537 \\
\hline Manisa & 75.833 & 25.544 & 644.380 & 518.200 & 3484.75 & 1238.73 \\
\hline Mardin & 27.583 & 23.446 & 169.110 & 331.830 & 799 & 799.193 \\
\hline Mersin & 70.166 & 19.324 & 369.165 & 287.659 & 1553.417 & 486.498 \\
\hline Muğla & 51.25 & 33 & 327.273 & 163.714 & 2429.667 & 841.794 \\
\hline Muş & 9.583 & 9.652 & 109.722 & 295.544 & 244.25 & 248.938 \\
\hline Nevşehir & 16.75 & 8.214 & 51.210 & 47.381 & 462.333 & 193.209 \\
\hline Niğde & 17.75 & 8.884 & 77.811 & 74.746 & 601.333 & 392.829 \\
\hline Ordu & 23.916 & 13.720 & 126.319 & 175.374 & 877.75 & 695.762 \\
\hline Osmaniye & 18.916 & 10.405 & 213.448 & 218.404 & 685.25 & 519.100 \\
\hline Rize & 9.916 & 5.743 & 77.267 & 72.893 & 289.083 & 208.214 \\
\hline Sakarya & 41.666 & 10.932 & 429.391 & 358.213 & 2232 & 779.317 \\
\hline Samsun & 36.583 & 16.811 & 362.602 & 707.405 & 1135.083 & 541.200 \\
\hline Siirt & 6.583 & 4.776 & 79.599 & 135.189 & 259.083 & 223.094 \\
\hline Sinop & 8.416 & 7.440 & 125.539 & 340.289 & 292.583 & 320.061 \\
\hline Sivas & 35.583 & 19.727 & 144.094 & 155.621 & 984.75 & 701.892 \\
\hline Şanlıurfa & 37.083 & 34.051 & 182.882 & 232.832 & 1351.333 & 1588.73 \\
\hline Şırnak & 8.416 & 4.718 & 80.723 & 130.460 & 230.083 & 135.224 \\
\hline Tekirdağ & 94.416 & 29.324 & 747.271 & 388.259 & 4668.417 & 2265.22 \\
\hline Tokat & 23.25 & 13.876 & 133.665 & 155.691 & 743.75 & 486.840 \\
\hline Trabzon & 28.75 & 14.936 & 169.670 & 154.060 & 672.916 & 322.463 \\
\hline Tunceli & 3.5 & 3.529 & 21.412 & 35.143 & 61 & 62.544 \\
\hline Uşak & 20.583 & 8.826 & 107.948 & 105.554 & 578.5 & 336.817 \\
\hline Van & 21.75 & 19.591 & 104.483 & 98.560 & 652.25 & 461.411 \\
\hline Yalova & 14.75 & 11.071 & 197.424 & 231.573 & 735.333 & 843.620 \\
\hline Yozgat & 15 & 8.045 & 41.072 & 34.307 & 427.083 & 236.225 \\
\hline Zonguldak & 22.833 & 8.526 & 276.154 & 246.277 & 1015.583 & 734.938 \\
\hline
\end{tabular}

( Kaynak: Ekonomi Bakanlığı, Teşvik Uygulama ve Yabancı Sermaye Genel Müdürlüğü) 


\subsection{Birim Kök Testleri}

Birim kök testleri, zaman serileri analizinde yaygın bir şekilde kullanılmakla birlikte, son yıllarda panel veri analizinde de ilgi görmektedir. Panel veri analizinde zaman serisi analizinde olduğu gibi değişkenlerin birim kök içerip içermediği incelenmelidir. Çünkü birim kök içeren serilerle elde edilecek regresyon tahminleri güvenilir olmamakta, sahte veya yanıltıcı tahminler ortaya çıkabilmektedir (Sandalcılar, 2012:168). Bu çalışmada, Im, Peseran, Shin (2003) ve Levin,
Lin, Chu (2002) birim kök testlerinden yararlanılmıştır. Kullanılan değişkenlere ait birim kök testleri Tablo 4'de sunulmuştur. Im, Pesaran, Shin (2003) ve Levin, Lin, Chu (2002) birim kök testlerinin sonuçları genel olarak değerlendirildiğinde, analize dâhil olan tüm değişkenlerin düzeyde durağan, yani I(0) oldukları anlaşılmaktadır. Serilerin düzey değerlerinde durağan olması, istihdam, teşvik sayısı ve sabit yatııımlar arasındaki ilişkinin analiz edilmesini mümkün kılmaktadır.

Tablo 4: Birim Kök Testleri

\begin{tabular}{|l|c|c|c|c|c|c|}
\hline \multicolumn{1}{|c|}{ Değişkenler } & \multicolumn{2}{c|}{ Istihdam } & \multicolumn{2}{c|}{ Sabit Yatırım } & \multicolumn{2}{c|}{ Teşvik belge sayısı } \\
\hline & Sabitli & Sabitli ve Trendli & Sabitli & Sabitli ve Trendli & Sabitli & Sabitli ve Trendli \\
\hline Levin, Lin \& Chu (t istatistiği) & $-12,90^{*}$ & $-12,19^{*}$ & $-4,40^{*}$ & $-9,21^{*}$ & $-10,93^{*}$ & $-13,24^{*}$ \\
\hline Im, Pesaran and Shin (W-istatistiği) & $-6,84^{*}$ & $-5,52^{*}$ & 1,73 & $-3,86^{*}$ & $-4,21^{*}$ & $-4,32^{*}$ \\
\hline
\end{tabular}

( Not: ${ }^{*} p<.01,{ }^{* *} p<.05,{ }^{* * *} p<.10$, Gecikme uzunluğu SC kriterine göre belirlenmiştir.)

\subsection{Bulgular}

$\mathrm{Bu}$ çalışmada daha önce de belirtildiği gibi, Türkiye'de 2001-2012 yılları arasında 81 ilde düzenlenen yatırım teşvik belgelerinin ve sabit yatırımlarının istihdama olan etkisinin panel regresyon model kullanılarak incelenmesi amaçlanmıştır. Bu amaçla elde edilen model Tablo 5'te verilmiştir.

Tablo 5'te sabit etkiler modeli ve birimler arası korelasyona ve farklı varyansa izin verildiği durumda elde edilen esnek genelleştirilmiş en küçük kareler regresyon modeli görülmektedir. Tablo 5'te de görüldüğü gibi Hausman testi, panel veri analizinde kullanılan modellerden sabit etkiler modelinin kabul edilmesi gerektiği- ni gösterir. Aynı zamanda F testi, birim etkinin varlığını yani havuzlanmış regresyon modeline göre sabit etkiler modelinin seçilmesi gerektiğini göstermektedir. Ayrıca modelin varsayımları incelendiğinde, Modifiye edilmiş Wald testi ile farklı varyans olduğu sonucuna varılmıştır. Breusch-Pagan LM testi, birimler arası korelasyonun varlığını göstermektedir. Bu çalışmada elde edilen sabit etkiler modelinde farklı varyans ve birimler arası korelasyon söz konusu olduğu için sabit etkiler modeli yerine bu varsayımlara karşı dirençli tahminciler veren esnek genelleştirilmiş en küçük kareler regresyonu elde edilmiştir. Ayrıca Baltagi-Wu LBI testi modelde otokorelasyon olmadığını göstermektedir.

Tablo 5: Sabit Etkiler Modeli ve Esnek Genelleştirilmiş En Küçük Kareler Tahmin Modeli

\begin{tabular}{|c|c|c|c|c|c|c|c|c|}
\hline \multirow[b]{2}{*}{ Değişkenler } & \multicolumn{4}{|c|}{ Sabit Etkiler Modeli } & \multicolumn{4}{|c|}{ Esnek Genelleştirilmiş EKK Modeli } \\
\hline & Katsayı & Std. Hata & z değeri & $\mathrm{P}>|\mathrm{z}|$ & Katsayı & Std. Hata & z değeri & $\mathrm{P}>|\mathrm{z}|$ \\
\hline Teşvik belge sayısı & 0.774 & 0.053 & $14.52^{* * *}$ & 0.000 & 0.828 & 0.070 & $11.91^{* * *}$ & 0.000 \\
\hline Sabit yatırım & 0.206 & 0.025 & $8.35^{* * *}$ & 0.000 & 0.247 & 0.036 & $6.82^{* * *}$ & 0.000 \\
\hline Sabit & 3.144 & 0.105 & $29.81^{* * *}$ & 0.000 & 2.714 & 0.122 & $22.2^{* * *}$ & 0.000 \\
\hline Gözlem sayısı & 972 & & & & 972 & & & \\
\hline Grup sayısı & 81 & & & & 81 & & & \\
\hline Zaman periyodu & 12 & & & & 12 & & & \\
\hline Wald $x^{2}(2)$ & 516.10 & & & 0.000 & & & & \\
\hline F test istatistiği & 2.50 & & & 0.000 & & & & \\
\hline Hausman test istatistiği & 27.83 & & & 0.000 & & & & \\
\hline \multicolumn{9}{|l|}{ Farklı varyans testi } \\
\hline Modified Wald test- $X^{2}(81)$ & 11626.22 & & & 0.000 & & & & \\
\hline \multicolumn{9}{|l|}{ Otokorelasyon testi } \\
\hline Baltagi-Wu LBI & 1.98 & & & & & & & \\
\hline \multicolumn{9}{|l|}{ Birimler arası korelasyon } \\
\hline $\begin{array}{l}\text { Breusch-Pagan } \\
\text { LM test of independence- } X^{2}(3240)\end{array}$ & 5550.41 & & & 0.000 & & & & \\
\hline
\end{tabular}

( Not: ${ }^{* * *} p<.01,{ }^{* *} p<.05,{ }^{*} p<.10$.) 
Elde edilen modelin genel olarak anlamlılığını gösteren Wald istatistiği oldukça yüksek ve anlamlıdır. Esnek genelleştirilmiş en küçük kareler modelinden elde edilen bulgulara göre, hem teşvik sayısının hem de sabit yatırımların istihdam üzerindeki etkisi istatistiki olarak anlamlı ve istihdam üzerindeki etkisi pozitiftir. Elde edilen bu sonuç, Ay (2005)'ın 19802003 yıllarında Türkiye'de yatırım teşviklerinin toplam sabit sermaye yatırımlarını pozitif yönde etkilediği, Akan ve Arslan (2008)'ın Doğu Anadolu Bölgesinde uygulanan teşvikli yatırımlar ile istihdam arasında doğrusal bir ilişkinin olduğunu ve teşvikli yatırımların bölgedeki istihdamı arttırdığı ve Schalk ve Gerhard (2000)'ın Almanya'da bölgesel yatırım teşviklerinin istihdamı olumlu etkilediği bulgusunu destekler niteliktedir. Gelişmiş ülkeler de dahil olmak üzere tüm dünyada birçok sektöre devlet tarafından teşvik politikaları uygulanmaktadır. Bu politikalar doğru bir şekilde planlanırsa teşviklerin ekonomiye ve dolayısıyla istihdama önemli katkıları olacaktır (Ayan, 2012:52). Ülkelerin ve ülke içerisindeki bölgelerin kalkınma hızlarını arttırmada yatırımlar büyük önem arz etmektedir. Bu nedenle ülkeler, özellikli bölgelerde ve özellikli sektörlerde yatırımları teşvik etmek için özel önlemler almaktadır. Ülkelerin yatırım teşviklerine başvurmasında birçok neden bulunmaktadır. Bunların en gerçekçisi yatırım teşvikleri ile ulaşılmak istenen iki temel amaçtan bahsedilebilmektedir (Karakurt, 2010:149150).

- İktisadi amaç: ana hedef, uzun vadede gerçekleşecek olan iktisadi gelişmelerdir. Bu amaç doğrultusunda önemli olan, kısa vadede istihdam sağlama ve ekonomik getiri fonksiyonundan daha çok belirli bir öğrenim/ üretim sürecinin tetiklenmesi, yeni bir üretim yapısının ya da teknolojinin ülkeye kazandırılması, alışkanlıkların kazanılması gibi etkilerden söz edilebilmektedir.

- Sosyal amaç: amaç, doğrudan iktisadi gelişmeden daha çok kamu gereklerinin yerine getirilmesi daha büyük önem taşımaktadır. Bölgelerarası dengesizliklerin giderilmesi, evrensel hizmet ya da bazı tür istihdam politikalarının geliştirilmesi bu amaç doğrultusunda gerçekleştirilmektedir. Devlet bu şekilde bir politika izleyerek, az gelişmiş bölgelerde normal şartlar altında özel sektör açısından kârlı olmayacak, ancak sosyal açıdan önem taşıyan yatırımların yapılması için destek verecektir.

\section{SONUÇ}

Küreselleşme, serbest piyasa ekonomisinin dünya ekonomilerinde yayılımını destekleyen en önemli kavramlardan biridir. Hızla değişen dünyamızda küresellik, her alanda olduğu gibi iktisat alanında da devinimi zorunlu kılmaktadır. Giderek artan uluslararası rekabet ülkelerin sürekli olarak kendilerini geliştirmelerine neden olmaktadır. Bu gelişim sürecinde ülkeler ekonomik güç elde etmek için bazı yollara başvurmaktadır. Bu yollardan biri de teşviklerdir. Son zamanlarda ülkeler refahını, gelişmişlikleri arttırmak için teşviklere sıkça başvurmakta hatta hükümetler politikaları içerisinde teşviklere de yer vermektedir. Ülkemizde önemli oranlarda yatırım teşvikleri uygulanmaktadır. Türkiye'de uygulanan yatırım teşvikleri ile istihdam politikaları birbirlerinden etkilenmektedir.

Bu çalışmada, gelişmekte olan ve gelişmiş ülkelerde ülkenin refahını arttırmak, kalkınmalarını desteklemek ve bölgesel dengesizlikleri ortadan kaldırmak için uygulanan teşviklerin ve sabit yatırımlarım istihdam üzerinde etkisi incelenmiştir. Analizlerde 2001-2012 yılları arasında 81 ilde uygulanan yatırım teşvik belgeleri adedi, sabit yatırım tutarları ve istihdam verileri kullanılmıştır. 2001 yılı ve sonrası dönemin özelliklerine bakıldığında sanayileşme politikaları çerçevesinde yatırım teşvikleri ve sabit yatırımların istihdamı desteklediği görülmektedir. Bu çalışmadan elde edilen bulgular sonucunda teşvik sayısının ve sabit yatırımların istihdam üzerindeki etkisi anlamlı ve pozitif bulunmuştur. Akan ve Arslan (2008)'ın, Doğu Anadolu Bölgesinde uygulanan teşvikler ile istihdam arasındaki ilişkiyi incelediği ve teşvikli yatırımlar ile istihdam arasında doğrusal bir ilişkinin olduğu ve teşvikli yatırımların bölgedeki istihdamı arttırdığı ve Schalk ve Gerhard (2000)'ın Almanya'da bölgesel yatırım teşviklerinin istihdama olumlu etkilediği sonuçları ile paralellik göstermektedir. Ayrıca bu çalışmanın konusunu oluşturan teşvik ve sabit yatırımların istihdamla olan ilişkisi, ekonomi politikalarının hedeflerini destekler niteliktedir. İşletmelerin kârlılığını artırmaya ve yatırımların maliyetini düşürmeye yönelik teşvik tedbirleri, uygulandığı geri kalmış bölgeleri, girişimciler için daha cazip hale getirerek ekonomik kalkınmaya katkıda bulunacaktır. Fakat teşvik tedbirlerinin sadece geri kalmış bölgeleri cazip hale getirip gelişmesini sağlamak amacıyla değil geri kalmış ülkelerde ülkenin gelişmesi için önemli olan bazı faaliyetleri ya da bazı sektörleri teşvik edici uygulamaları da söz konusudur. Böylelikle hem bölgelerarası dengesizlik azaltılacak, hem de geri kalmış bölgelerin kalkınması desteklenecektir (Gülmez ve Yalman, 2010:238).

Gelişmekte olan ülkeler arasında yer alan Türkiye'yi gelişmiş ülkeler seviyesine ulaştırmak için uygulanan sanayi politikalarından teşviklerin ve sabit yatırımların istihdamı arttırıcı etkisi göz önünde bulundurulmalıdır. Ayrıca teşviklere, gelecek yıllarda daha da önem verilemesinin gerekli olduğu elde edilen bulgular neticesinde görülmektedir. 


\section{KAYNAKLAR}

Akan, Y. ve Arslan, İ. (2008) “Türkiye’de Sektörel Yatırım Teşvik Belgeleri ile İstihdam Analizi: Doğu Anadolu Bölgesi Üzerine Bir Uygulama (1980-2006)" Çalışma ve Toplum, 1: 107-119.

Armstrong, H.W. ve Taylor, J. (2000) Regional Economics and Policy, 3. Baskı, Oxford, Blackwell.

Ardıç, A.A. (1994) “Türkiye'de 1980 Sonrası yatırım Teşvik Uygulamaları ve Tarımsal Yatırımlardaki Gelişmeler" Tarm Ekonomisi Dergisi, 2:62-74.

Ay, H.M. (2005) "Yatırım Teşviklerinin Sabit Sermaye Yatırımları Üzerindeki Etkisi” Selçuk Üniversitesi Karaman İktisadi ve İdari Bilimler Dergisi, 5 (2):176-184.

Ayan, E.(2012) “Türk Bankacilık Sektöründe İstihdam Analizi ve İstihdamın Arttırılması Olanakları", Business and Economics Research Journal, 3(1):41-57

Ayele, S. (2006) "The Industry and Location Impacts of Investment Incentives on Sme's Start-up in Ethiopia” Journal of International Development, 18:1-13.

Baltagi, B.H. (1995) Econometric Analysis of Panel Data, England, John Wiley \& Sons Ltd.

Baltagi, B.H. (2008) "Econometric Analysis of Panel Data” U.K, John Wiley \& Sons Ltd.

Bayraktutan, Y. ve Demirtaş, I. (2011) “Gelişmekte Olan Ülkelerde Cari Açığın Belirleyicileri: Panel Veri Analizi" Kocaeli Üniversitesi Sosyal Bilimler Enstitüsü Dergisi, 22(2):1-28.

Blomström, M., Kokko, A. ve Mucchielli, J.L. (2003) "The Economics of Foreign Direct Investment Incentives" Foreign Direct Investment in the Real and Financial Sector of Industrial Countries, 37-60.

Bondonio, D. ve Greenbaum, R. T. (2006) "Do Business Investment Incentives Promote Employment in Declining Areas? Evidence from EU Objective-2 Regions" European Urban and Regional Studies, 13(3):225244.

Çetin, M. ve Ecevit, E. (2010) "Sağlık Harcamalarının Ekonomik Büyüme Üzerindeki Etkisi OECD Ülkeleri Üzerine bir Panel Regresyon Analizi” Doğuş Üniversitesi Dergisi, 11(2): 166-182.

Çiloğlu, İ. (1997) “Teşvik Sisteminin Değerlendirilmesi” Hazine Dergisi, 8:1-15.

Çiloğlu, İ. (2000) “Teşvik Politikasının Yönlendirme Gücü” Hazine Dergisi, 13:29-49.

Devlet Planlama Teşkilatı (1991) "Yatırım Teşviklerinin Tarihi Seyri ve Son On Y1lın İstatistikleri” Ankara, Teşvik ve Uygulama Başkanlığı.
Devlet Planlama Teşkilatı (2006) Dokuzuncu Kalkınma Planı (2007-2013), Ankara.

Devlet Planlama Teşkilatı (2007) “Dokuzuncu Kalkınma Planı Devlet Yardımları Özel İhtisas Komisyonu Raporu” Ankara, DPT Yayınları.

Dicken, P. ve Ticknell, A. (1992) "Competitors Or Collaborators? The Structure of Inward Investment Promotion in Northern England" Regional Studies, 26:99114.

Dougherty, C. (2007) Introduction to Econometrics NewYork, Oxford University Press.

Erkan, V. (1999) “Dis Proje Kredisi Kullanan Kamu Yatırımlarının Gelisimi ve Değerlendirilmesi (19881997)" DPT Uzmanlık Tezi, Ankara DPT, İktisadi Sektörler ve Koordinasyon Genel Müdürlüğü.

Greene, W.H. (2003) Econometric Analysis New York, McMillan.

Gujarati, D.N. (2004) Basic Econometrics, New York, McGraw-Hill.

Gülmez, M. ve Yalman, İ.N. (2010) "Yatırım Teşviklerinin Bölgesel Kalkınmaya Etkileri” Atatürk Üniversitesi İIBF Dergisi, 24(2):235-257.

Hsiao, C. (1985) "Benefits and Limitations of Panel Data” Econometric Reviews, 4(1):121-174.

Hsiao, C. (2003) "Analysis of Panel Data” New York, Cambridge University Press.

Im, K.S., Pesaran, H. M. ve Shin, Y. (2003) “Testing for Unit Roots in Heterogeneous Panels" Journal of Econometrics, 115:53-74.

Jonhston, J. ve Dinardo, J. (1997) Econometric Methods, New York, McGraw-Hill.

Kalkınma Bakanlığı (2013) Onuncu Kalkınma Planı (2014-2018), Ankara.

Karaaslan, A. ve Yildız, F. (2011) “Telekomünikasyon Sektöründe Regülasyon ve Özelleştirmenin Etkileri: OECD Ülkeleri Üzerine Ampirik Bir Çalışma” Yönetim ve Ekonomi, 18(2):1-21.

Karaca, B. (2004) “Türkiye'deki Bölgelerarası Gelişme Farklarının Azaltılmasında Teşvik Uygulamalarının Etkinliği” Yayımlanmamış Yüksek Lisans Tezi, İstanbul, Marmara Üniversitesi Sosyal Bilimler Enstitüsü.

Karakurt, A. (2010) "Küresel Kriz Ortamında Yatırım Teşvikleri”, Ankara Üniversitesi SBF Dergisi, 65-2:143-163.

Kennedy, P. (2006) "Ekonometri Klavuzu” Çev. Muzaffer Sarımeşeli ve Şenay Açıkgöz, 5.Baskı, Ankara, Gazi Kitabevi. 
Levin, A., Lin, C.F. ve Chu, C.S.J. (2002) "Unit Root Tests in Panel Data: Asymptotic and Finite Sample Properties" Journal of Econometrics, 108:1-24.

Liard-Muriente, C.F. (2007) "US and EU Experiences of Tax Incentives" Area, 39 (2):186-194.

Martin, R. (1998) "Regional Incentive Spending for European Regions” Regional Studies, 32 (6):527-536.

Narin, M. (2012) "Türkiye'de Yatırımlar ve Yatırım Teşvikleri” Dokuz Eylül Üniversitesi, 3. Ulusal İktisat Kongresi, 29 Şubat-2 Mart, İzmir.

Özer, M ve Biçerli, K. (2003) "Türkiye'de Kadın İşgücünün Panel Veri Analizi” Anadolu Üniversitesi Sosyal Bilimler Dergisi, 3(1):55-86.

Peters, A. ve Fisher, P. (2004) "The Failures of Economic Development Incentives" Journal of the American Planning Association, 70(1):27-37.

Petrakis, P. (2012) "Human Incentives" The Greek Economy and the Crisis, 233-268.

Sandalcilar, A.R. (2012) "BRIC Ülkelerinde Ekonomik Büyüme ve İhracat Arasındaki İlişki: Panel Eşbütünleşme ve Panel Nedensellik" Süleyman Demirel Üniversitesi İktisadi ve İdari Bilimler Fakültesi Dergisi, 17(1):161-179.

Schalk, H.J. ve Gerhard, U. (2000) "Regional Investment Incentives in Germany: Impacts on Factor and Growth" The Annals of Regional Science, 34:173-195.

Schwartz, D., Pelzman, J. ve Keren, M. (2008) “The Ineffectiveness of Location Incentive Programs: Evidence from Puerto Rico and Israel" Economic Development Quarterly, 22(2): 167-179.

Serdengeçti, T. (2000) Türkiye'de Yatırım Teşvik Uygulamaları, Ankara, T.C. Başbakanlık Hazine Müsteşarlığı Teşvik ve Uygulama Genel Müdürlüğü Yayınları.

Şahin, M. ve Uysal, Ö. (2011) "Bölgesel Kalkınma Çerçevesinde Yatırım Teşviklerinin Shift-Share Analizi" Maliye Dergisi, 160:111-138.
Tatoğlu, F. (2012) "Panel Veri Ekonometrisi" İstanbul, Beta Basım A.Ş.

Türkiye Cumhuriyeti, Ekonomi Bakanlığı, Yatırım Teşvik İstatistikleri, http://www.ekonomi. gov.tr/index.cfm?sayfa=EE7EE7B 1-D8D3-856645201CE77E5F0FDD (14.03.2013).

UNCTAD (2000) “Tax Incentives and Foreign Direct Investment: A Global Survey” United Nations, New York.

Verdugo, A.R. (2006) "Regional Incentives For Investment in Mexico: The Accelerated Depreciation Reforms" 99th. Annual Conference on Taxation.

Yalçın, H. (1999) Yatırım İndirimi, İstanbul, Kılavuz Yayınevi.

Yavan, N. (2011a) “Teşviklerin Sektörel ve Bölgesel Analizi: Türkiye Örneği” Ekonomik ve Mali Araştırma Yarışması, Ankara, Maliye Hesap Uzmanları Vakfı Yayınları.

Yavan, N. (2011b) “Teşviklerin Bölgesel Ekonomik Büyüme Üzerindeki Etkisi: Ampirik Bir Analiz” Ekonomik Yaklaşım, 22(81):65-104.

Yavan, N. (2012) “Türkiye'de Yatırım Teşviklerinin Bölgesel Belirleyicileri: Mekânsal ve İstatistiksel Bir Analiz" Coğrafi Bilimler Dergisi, 10(1):9-37.

Yavuz, A. (2010) "Bir Maliye Politikası Aracı Olarak Yatırım Teşviklerinin Rekabet Koşulları Altında Özel Kesim Yatırımları ve İstihdam Üzerine Etkisi: Ekonometrik Bir Analiz" Süleyman Demirel Üniversitesi İktisadi ve İdari Bilimler Fakültesi Dergisi, 15(1):83-101.

Yayar, R. ve Demir, Y. (2012) "Bölgesel Kalkınma ve Yatırım Teşvikleri: Tokat İlinde Bir Uygulama” Erciyes Üniversitesi İktisadi ve İdari Bilimler Fakültesi Dergisi, 39:119-146. 
